The Research Journal of the Costume Culture

[Original Article]
Received November 30, 2016 Accepted December 31, 2016

${ }^{\dagger}$ Corresponding author (sha5@utk.edu)

ORCID

JEE-SUN PARK

http://orcid.org/0000-0002-6021-2836

Sejin $\mathrm{Ha}$

http://orcid.org/0000-0001-7915-7286

This work was supported by the Incheon National University Research Grant in 2014.

\author{
Jee-Sun Park and Sejin $\mathrm{Ha}^{\dagger *}$ \\ Dept. of Fashion Industry, Incheon National University, Korea \\ Dept. of Retail Hospitality and Tourism Management, \\ The University of Tennessee, USA*

\section{SNS 브랜드 페이지에서 소비자-브랜드 관계 형성에 미치는 영향 요인 분석 \\ - 준사회적 상호작용 역할을 중심으로 -}

\author{
박 지 선 · 하 세 진 ${ }^{\dagger *}$ \\ 인천대학교 패션산업학과 \\ Dept. of Retail Hospitality and Tourism Management, \\ The University of Tennessee, USA*
}

\begin{abstract}
The rapid growth in the popularity of social media sites has meant that social media has become an important communication channel for brands. Brands create brand pages on social media to cultivate positive and strong relationships with consumers. This study seeks to enhance our understanding of how fashion brand pages in social media foster consumer-brand relationships by exploring the factors that affect the development of consumer-brand relationships. Drawing on the parasocial interaction theory, this study proposes parasocial interaction as a key factor of this process. Specifically, this study proposes four antecedents (vividness, interactivity, social presence, and focused attention) of consumers' parasocial interaction with brand pages, which further affects consumer responses in terms of affective engagement and brand loyalty. An online survey was administered with consumers who have followed and visited at least one fashion brand page via a social networking site (SNS). Structural equation modeling revealed that consumers' perceptions of vividness, interactivity, social presence, and focused attention on a fashion brand page positively affected their feelings towards parasocial interaction with the brand page, which in turn led to their affective engagement with the brand page and consequent brand loyalty. These findings suggest that consumers build relationships of varying degrees with brand pages in a similar manner to that with people, which leads to their development of a positive relationship with the brand. This study concludes with discussions and practical implications.
\end{abstract}

Keywords: Social media(소셜미디어), brand page(브랜드페이지), consumer-brand relationship(소비자-브랜드 관계), parasocial interaction(준사회적 상호작용) 


\section{Introduction}

소셜 네트워크 사이트(SNS) 사용자들은 매년 급속 한 속도로 증가하고 있다. 최근 자료에 의하면 전 세 계 소셜 미디어 사용자들은 매년 $10 \%$ 이상의 증가율 을 보이며 꾸준히 증가하고 있으며, 사용자수는 2019 년 27억명에 이를 것이라 예상된다(Statista, 2016a). $\mathrm{SNS}$ 는 많은 소비자들이 사용하는 주요 채널이 되었 으며, 소비자들이 브랜드 관련 정보를 획득하고 공유 하는 방법을 변화시켰다(Hennig-Thurau et al., 2010). 이는 브랜드 마케터에게 소비자들과 직접적인 소통 을 통한 관계를 형성할 수 있는 기회를 제공한다(HennigThurau et al., 2010; Labrecque, 2014; Lee \& Cho, 2014). 기업들은 SNS 공간에서 브랜드 계정, 즉 브랜 드 페이지(brand (fan) page)를 만들어 마케팅 메시지 및 프로모션 정보를 전달하고 소비자들로 하여금 브 랜드 제품과 서비스에 대한 의견을 자유롭게 공유할 수 있는 환경을 제공하며, 소비자들과의 직접적인 커 뮤니케이션을 통한 우호적 관계를 형성하고자 노력 한다. 브랜드는 브랜드 페이지를 통하여 소비자들에 게 브랜드 정보 및 광고 메시지를 전달할 뿐 아니라, 팬의 친구들에게 브랜드 관련 정보를 노출할 수 있으 므로 잠재 소비자들에게도 브랜드에 대한 인지도를 높이고, 호의적인 이미지를 형성할 수 있다. 친구를 통한 브랜드 노출은 전통적인 광고보다 소비자들의 저항이 적으며, 소비자들은 브랜드 페이지에서 제공 하는 감성 이미지 및 동영상 등 다이너믹하고 생생한 콘텐츠를 공유하며, 즐거움을 느끼고 감정적인 태도 를 형성하기도 한다. 점점 소셜 미디어를 통해서 브 랜드 관련 정보를 비율이 높아지며(Statista, 2016b), 브랜드 페이지에서 소비자들과의 우호적인 관계 형 성은 중요한 주제가 되었다.

소비자들이 브랜드 페이지에서 팬이 되는 주요 이 유로서 Kalehoff(2013)는 소비자들의 브랜드에 대한 감정적이고 관계 지향적인 가치로 설명하였다. 감정 적인 자산이 강한 디즈니, 코카콜라, 나이키 등이 다 수의 팬을 보유한 대표적인 예라 할 수 있다. 물리적 인 제약이 없는 디지털 환경에서 소비자들의 커뮤니 티 활동은 활발해지고, 이러한 활동은 소비자들에게 다양한 가치를 제공하고, 감정적인 관계를 형성할 수 있는 좋은 기회가 된다. 소비자들과 직접적인 소통이
가능한 브랜드 페이지는 소비자-브랜드 관계 형성에 서 중요한 역할을 한다(Hennig-Thurau et al., 2010; Kalehoff, 2013; Labrecque, 2014). 이에 브랜드 마케 터들은 활발한 상호작용과 우호적인 소비자-브랜드 관계 형성을 돕는 브랜드 페이지 환경을 디자인하여 소비자들과의 활발한 상호작용을 촉진하고자 많은 노력을 한다. 하지만 SNS 브랜드 페이지에서 활동하 는 소비자들에 대한 이해를 위한 체계적인 연구는 부 족한 실정이다. 소셜 미디어 환경에서 활발한 상호작 용 및 이를 통한 성공적인 소비자-브랜드 관계 형성 을 위해서는 어떤 환경이 필요한 것인가? 이 질문에 답하기 위하여 본 연구는 미디어가 중재하는 커뮤니 케이션을 설명하는 대표적인 이론 중 하나인 준사회 적 상호작용이론(parasocial interaction theory)을 이 용하여 브랜드 페이지에서 소비자들의 감정적인 상 호작용 및 이를 통한 소비자-브랜드 관계 형성 과정 을 설명하고자 한다.

준사회적 상호작용 이론은 미디어 소비자들이 등 장인물과 미디어를 통한 커뮤니케이션이 실제 대면 관계와 유사하다고 느끼는 현상을 설명하는 이론으 로서(Horton \& Wohl, 1956), 미디어 중재 커뮤니케 이션의 하나인 SNS 브랜드 페이지를 통한 소비자들 과의 상호작용과 관계 형성에 대한 현상을 설명하기 에 적절하다고 판단된다. $\mathrm{TV}$ 프로그램, 뉴스와 같은 전통적인 미디어 페르소나와 소비자의 가상의 사회 적 관계를 설명하는 개념으로 출발한 준사회적 상호 작용은 TV 홈쇼핑 채널, 브랜드 웹사이트, 온라인 커뮤니티 및 $\mathrm{SNS}$ 와 같은 디지털 환경에서 지각된 호스트, 브랜드, 다른 소비자들, 또는 웹사이트와의 관계를 설명하는 개념으로 적용되어 제시되었다 (Ballantine \& Martin, 2005; Hoerner, 1999; Koening \& Lessan, 1985; Labrecque, 2014; Rubin \& Perse, 1987a, 1987b; Stephens, Hill, \& Bergman, 1996). 본 연구는 선행연구에서 나아가 소비자들이 브랜드 페 이지에 대하여 친근한 감정을 느끼며 가상의 상호작 용을 느낄 수 있으며, 소비자들이 지각하는 준사회 적 상호작용의 정도가 소비자-브랜드 관계 형성에 미치는 영향을 제시하고 검증하고자 한다. 더욱이 소비자들이 지각하는 준사회적 상호작용에 영향을 미치는 요소들을 제시하고, 영향 관계를 알아보고자 한다. 


\section{Background}

\section{Parasocial interaction}

준사회적 상호작용(parasocial interaction)은 미디 어가 중재하는 커뮤니케이션 환경에서 미디어 소비 자들이 미디어의 등장인물과 심리적으로 형성된 가 상의 인간관계를 설명하는 개념이다(Horton \& Wohl, 1956). 준사회적 상호작용 이론에 따르면, 미디어 소 비자들은 미디어에서 제시한 페르소나와 가상의 관 계를 맺으며, 이러한 가상의 상호관계에서 마치 면대 면 관계와 비슷한 정서적 밀착관계를 보인다고 한다 (Horton \& Wohl, 1956; Rubin, Perse, \& Powell, 1985; Stern, Russell, \& Russell, 2007). 예를 들어 드 라마 시청자들은 텔레비전에서 제시된 사회배경 안 에서 등장인물들 사이의 다양한 인간관계를 보며, 등 장인물의 역할에 따라 제시된 페르소나에 공감을 하 기도 격분을 하기도 하며, 마치 현실 상황에서 만날 수 있는 사람과 관계를 맺는 착각을 느끼기도 한다. Perse and Rubin(1989)은 소비자가 매력을 느끼는 미 디어 페르소나와의 가상의 관계는 자율적인 결정으 로 성립되며, 이 관계에서 미디어 페르소나가 소비자 의 상대 역할을 수행하므로, 이러한 가상의 관계가 친구 사이와 유사할 수 있다고 설명한다. 선행연구에 의하면, 미디어를 통한 관계에서 느끼는 친밀한 감정 이 클수록 미디어 소비자들은 이 관계를 유지하기 위 하여 지속적으로 미디어를 소비하고, 나아가 소비량 을 늘리기도 한다(Rubin et al., 1985). 더욱이 이러한 의존적인 관계는 방송이 종료된 시점 이후에도 지속 되기도 한다(Skumanich \& Kintsfather, 1998).

준사회적 상호작용의 역할은 텔레비전 TV 드라마 (Rubin \& Perse, 1987a), 뉴스(Koening \& Lessan, 1985; Levy, 1979; Rubin \& Perse, 1987b) 및 TV 홈 쇼핑 채널(Stephens, et al., 1996) 등 다양한 미디어 환경에서 검증되었다. 미디어 환경이 온라인과 모바 일 등 디지털 기기로 확대됨에 따라 새로운 디지털 환경에서의 준사회적 작용의 역할에 대한 연구가 진 행되었다. Ballantine and Martin(2005)은 온라인 커뮤 니티에서 소비자들이 준사회적 상호관계를 형성하는 과정을 제시하였다. Powell, Richmond, and Williams (2011)는 사용자들이 정치 후보자 SNS를 통해 준사 회적 상호작용 관계를 형성하는 것을 보여주었고,
Labrecque(2014)는 SNS에서 소비자들이 지각하는 준 사회적 상호작용이 브랜드 충성도와 같은 장기적 관 계형성에 미치는 역할을 제시하였다. Hoerner(1999) 는 소비자들이 상업용 웹사이트를 사용하면서 해당 사이트에 대하여 사람과의 관계와 같은 친밀한 감정 을 느끼고, 사이트와 준사회적 상호작용 관계를 형성 할 수 있다는 것을 보여주었다.

소셜미디어 환경에서 소비자들은 컴퓨터 또는 모 바일 기기를 이용하여 언제 어디서든 브랜드 페이지 를 방문할 수 있으며, 브랜드 페이지를 통해 제시된 정보를 습득하고, 다른 소비자들과 공유하며, 다양한 경험을 할 수 있다. 텔레비전, 라디오, 영화 등 기존의 전통 미디어에서의 준사회적 관계는 피드백을 주고 받을 수 없는 일방적인 관계였지만(Horton \& Wohl, 1956), 소셜미디어는 브랜드 담당자 또는 다른 소비 자들과 피드백을 주고받을 수 있는 환경을 제공한다. 또한 전통적 미디어와는 다르게 등장인물은 없지만, 브랜드 또는 브랜드 페이지의 특성에 따라 해당 브랜 드를 선호하는 소비자들 및 브랜드 관계자들과 정보 를 공유할 수 있다는 특징이 있다. 이에 본 연구는 소 비자들이 상업용 웹사이트에서 준사회적 상호작용을 느끼는 것처럼(Hoerner, 1999), SNS 브랜드 페이지에 서도 준사회적 상호관계를 형성할 수 있을 것이라 제 안한다. 즉각적인 상호작용 또는 피드백을 통한 상호 작용이 가능한 소셜미디어의 특성에 따라 SNS 브랜 드 페이지에서 지각된 준사회적 상호작용의 역할은 소비자-브랜드 관계 형성에 더욱 중요할 것이다. 따 라서 본 연구는 준사회적 상호작용 이론을 이용하여 소비자들이 방문한 브랜드 페이지에서 지각되는 준 사회적 상호관계의 역할을 제시하고자 하며, 그 관계 의 정도가 소비자-브랜드 관계 형성에 미치는 영향을 검증하고자 한다.

\section{Antecedents of perceived parasocial interaction}

미디어 사용자들이 지각하는 준사회적 상호작용 정도는 미디어 특성에 의해서 영향을 받는다(Auter, 1992). 예를 들어 미디어 등장인물이 현실처럼 생생 하고 등장인물이 화면을 응시하여 마치 상호작용하 는 것 같을 때(Horton \& Wohl, 1956), 혹은 웹사이트 의 디자인, 정보 제시되는 스타일 등의 특성(Hoerner, 1999)이 등장인물 또는 웹사이트와의 지각된 준사회 
적 상호작용 정도에 영향을 미친다. 즉, 미디어 중재 커뮤니케이션 환경이 보다 실재 면대면 관계와 유사 할수록 준사회적 사회작용의 느낌이 강하다는 것이 다. 미디어에 중재된 커뮤니케이션 환경과 실재 면대 면 환경의 근본적인 차이는 비언어적 단서, 물리적 접근성, 쌍방의 피드백 등에서 찾을 수 있다. 이와 관 련하여 매체풍부성(media richness) 이론은 풍부한 매 체일수록, 즉 실재 면대면 커뮤니케이션 환경과의 차 이가 적은 매체일수록 소비자들의 실재감은 높아지 고, 이에 따라 커뮤니케이션 효율이 높아짐을 설명한 다(Daft \& Lengel, 1986; Rice, 1992). 매체풍부성 이 론에 따르면 쌍방의 피드백, 감각적인 단서 및 언어 적 다양성이 제공되는 매체, 즉 상호작용성(interactivity) 과 생생함(vividness)이 높은 매체일수록 풍부한 매체 라고 할 수 있다(Daft, Lengel, \& Trevino, 1987; Rice, 1992).

더욱이 일반적인 면대면 관계에서의 커뮤니케이션 은 서로 상대방에게 집중하고 피드백을 보내는 상호 작용이 존재한다는 특징이 있다. 커뮤니케이션 이론 에 따르면 사용자들은 면대면 환경과 유사한 미디어 환경에서 주의를 집중(focused attention)하고 사회적 실재감(social presence)을 지각하며, 마치 면대면 커 뮤니케이션과 유사하게 느끼고 행동한다(Daft \& Lengel, 1986; Lombard \& Ditton, 1997; Reeves \& Nass, 1996). 이에 브랜드 페이지를 통한 커뮤니케이션 환 경에서 실재 면대면 커뮤니케이션 환경과 유사하게 느끼게 하여 지각된 준사회적 상호작용 형성에 영향 을 미칠 수 있는 요인으로 소비자들의 지각된 집중된 주의와 사회적 실재감을 제시하고, 그 영향관계를 알 아보고자 한다. 특히 선행연구는 가상의 공간에서 사 용자들의 실재감을 높이는 주요한 영향 요인으로서 생생함과 상호작용성을 제시하였다(Choi, Miracle, \& Biocca, 2001; Coyle \& Thorson, 2001; Steuer, 1992). 즉, 가상의 공간에서 사용자들이 지각하는 생생함과 상호작용성은 사용자들로 하여금 직접적인 대면 커 뮤니케이션 경험과 보다 유사하다고 느끼게 하고, 이 는 사용자들의 가상의 관계 형성으로 이끌 것이다. 따라서 본 연구에서 소셜 미디어의 브랜드 페이지에 서 준사회적 작용에 영향을 미칠 수 있는 요인으로 생생함, 상호작용성, 사회적 실재감 및 집중된 주의를 제시하고, 그 영향관계를 알아보고자 하였다.

\section{1) Social presence}

사회적 실재감(social presence)은 사용자가 미디어 중재 커뮤니케이션 환경에서 미디어로 또는 커뮤니 케이션 환경으로부터 따뜻하고 인간적인 느낌을 지각 하는 정도를 말한다(Short, Williams, \& Christie, 1976). 사용자들은 컴퓨터를 마치 실제 사회적 행위자로 인 식하고 사용하는 경향이 있다(Reeves \& Nass, 1996). 이와 같은 지각하는 사회적 실재감이 높으면 미디어 중재 커뮤니케이션 환경에서 마치 면대면 커뮤니케 이션 관계와 유사하게 느끼는 경향이 있다(Nass \& Moon, 2000).

미디어 기기에서 제시되는 사회적 맥락의 단서들 과 관계 지향적인 정보들은 사용자들의 사회적 실재 감에 영향을 주게 된다. 예를 들어 가상의 공간에서 사람과 같은 사회적 행위자들과 상호작용을 하는 듯 한 상태는 실재감을 높이고, 가상세계에서 제시된 아 바타와 준사회적 상호작용을 하게 된다(Jin, 2010). 이러한 사회적 실재감은 마치 상대방이 나에게 응답 할 것 같고, 이로 인해 상호작용은 높아진다. 선행연 구는 중재된 미디어에서 느끼는 사회적 실재감이 사 용자들의 감각을 자극하고(Fortin \& Dholakia, 2005), 호의적인 감정을 유발하며(Shen \& Khalifa, 2012), 이 에 따라 사용자들은 미디어 환경에서 마치 사람을 대 하듯 상호작용을 하게 된다는 것을 보여주었다(Jin, 2010). 지각된 사회적 실재감이 높으면 사용자들이 상 호작용하는 로봇과 같은 동적인 기기뿐 아니라, 가상 의 공간에서 역시 매력을 느끼고 상호작용을 즐기게 된다(Jin, 2010; Lee, Peng, Jin, \& Yan, 2006).

SNS 브랜드 페이지는 사용자 개인을 비롯한 다수 의 소비자들과 브랜드 관계자들이 함께 참여하여 브 랜드와 제품을 비롯한 다양한 정보를 교환하는 공동 체적인 경험의 공간이다. 이러한 가상의 공동체 공 간에서 지각된 사회적 실재감에 따른 공동체적인 경 험은 제시된 다양한 콘텐츠 및 사용자들과 활발한 상호작용에 영향을 주게 된다(Piyathasanan, Mathies, Wetzels, Patterson, \& de Ruyter, 2015). 따라서 브랜 드 페이지에서 사용자들이 다양한 콘텐츠와 다른 소 비자들과의 상호작용을 하면서 지각된 사회적 실재 감이 높으면 브랜드 페이지에서 보다 따뜻하고 인간 적인 느낌을 받을 것이며, 이러한 느낌은 지각된 준 사회적 상호작용에 영향을 줄 것이다. 
가설 1: 지각된 사회적 실재감은 지각된 준사회적 상호작용에 정 $(+)$ 의 영향을 미칠 것이다.

\section{2) Focused attention}

집중된 주의(focused attention)은 개인이 대화, 일, 또는 게임 등 어떤 활동에 몰입하여 주의를 기울이는 정도를 말한다. 주의(attention)은 개인의 인지과정에 서 한 물체를 인지하고 지각하기 위하여 필요한 선행 단계로서(Goldstein, 2007), 커뮤니케이션 과정에서 증 폭기와 같은 역할을 하여 상호작용하는 대상에 대한 정보 인식 및 처리 과정의 효율을 증대시킨다(Johnson \& Proctor, 2004). 따라서 커뮤니케이션, 일, 또는 게 임과 같이 개인이 상호작용하는 활동에서 주의는 선 행되는 단계이며, 커뮤니케이션에서 중요한 역할을 한다.

집중된 주의는 사용자가 지각하는 몰입감과 강한 상관관계를 보이며, 미디어 환경에서 사용자의 집중 된 주의력은 몰입감과 유사한 형태로 이어진다(Bracken, Petty, \& Wu, 2014). 사람들은 자신의 주변 환경에 대 해서 의식적 또는 무의식적으로 지속적인 주의를 하 게 되지만, 개인의 주의력은 제한적이므로 하나의 대 상에 대해서 주의를 기울이게 되면 다른 것에 대한 주의력은 떨어지게 된다(Lang, 1990). 반대로 하나의 활동이나 일에 몰입하여 집중하는 것은 자신의 대부 분 자원을 한 곳으로 집중시킨다는 의미가 된다. 이 렇게 집중된 주의는 실재감을 높이고, 자신이 하는 행동에 몰입으로 이어지게 되어(Novak, Hoffman, \& Yung, 2000), 미디어 환경에서 사용자 경험의 질을 결정하는 중요한 변수이다(Biocca \& Delaney, 1995; Carù \& Cova, 2006).

준사회적 상호작용은 물리적 거리가 멀지만, 미디 어 페르소나에 대하여 밀착감을 느끼는 정도를 말한 다(Horton \& Wohl, 1956). 소비자들의 높은 집중된 주의는 관여도를 높이고 몰두하게 만들어 브랜드 페 이지에서 제시된 다양한 콘텐츠 및 다른 사용자들과 의 상호작용을 보다 활발하게 할 것이다. 따라서 브 랜드 페이지에서의 경험에서 소비자들의 집중된 주 의가 높으면 소비자들은 보다 활발한 상호작용을 하 고 있다고 느낄 것이며, 이러한 느낌은 지각된 준사 회적 상호작용에 영향을 줄 것이다.
가설 2: 지각된 집중된 주의는 지각된 준사회적 상 호작용에 정 $(+)$ 의 영향을 미칠 것이다.

\section{3) Perceived vividness}

지각된 생생함(perceived vividness)은 미디어에 중 재된 커뮤니케이션 환경에서 미디어의 특성으로 구 현된 감각적 단서들이 풍부한 미디어 환경에서 커뮤 니케이션 메시지 또는 미디어에 대하여 생생하게 느 끼는 정도를 말한다(Steuer, 1992). 소비자들은 미디 어에서 제공하는 감각적 차원과 종류가 많을수록, 그 리고 커뮤니케이션 맥락 단서들이 선명하게 양질로 제공될수록 해당 커뮤니케이션에 대해 느끼는 생생 함이 커진다(Daft \& Lenger, 1986; Daft et al., 1987; Steuer, 1992). 컴퓨터 중재 커뮤니케이션을 대상으로 한 선행연구는 웹사이트 사용자들의 지각된 생생함 은 실재감 향상과 이에 따른 커뮤니케이션 경험에 직 접적인 영향을 미친다는 것을 보여주었다(Coyle \& Thorson, 2001; Steuer, 1992). 구체적으로, 지각된 생 생함은 소비자들의 다중의 감각을 자극하여 주의를 집중시켜 몰입도를 높이고, 호의적인 감정과 태도를 유발한다(Fortin \& Dholakia, 2005; Shen \& Khalifa, 2012). 또한 지각된 실재감을 향상시키며(Coyle \& Thorson, 2001; Klein, 2003; Shen \& Khalifa, 2012), 비인간적인 미디어 중재 커뮤니케이션 환경에서 커 뮤니케이션 행위자들이 참여하고 있다는 느끼며, 지 각된 사회적 실재감을 높인다(Choi et al., 2001; Fortin \& Dholakia, 2005; Shen \& Kahlifa, 2012). 이러한 생 생함은 소비자들의 상호작용 관계의 양과 질을 향상 시켜 가상의 공간에서 활동을 촉진시킨다(Huang, 2016).

$\mathrm{SNS}$ 환경은 $\mathrm{TV}$, 라디오 등의 일방적인 성격이 강 한 미디어, 또는 불특정 다수를 대상으로 제공되어 커 뮤니케이션 행위자들의 익명성이 강한 웹사이트에 비 하여, 다양한 멀티미디어 콘텐츠가 지속적으로 제공 되어 보다 생생함이 높은 커뮤니케이션 환경이 조성 될 수 있다. 이러한 생생함의 특성을 SNS 브랜드 페 이지에 적용할 수 있다. 즉, 미디어 중재 환경에서의 선행연구를 바탕으로 SNS 브랜드 페이지에서 소비자 들이 브랜드 페이지에서 제시된 콘텐츠와 관련 글에 대해서 느끼는 생생함은 브랜드 페이지에서 주의를 집중시키고, 사회적 실재감 지각에 영향을 줄 것이라 
는 가설을 제시할 수 있다. 또한 커뮤니케이션에서 관여도를 높이고 호의적인 반응을 촉진하며, 실재감 을 높여 상호관계의 질을 향상시키는 생생함의 특성 은 준사회적 상호작용에 영향을 미친다(Giles, 2002). 따라서 SNS 브랜드 페이지에서 사용자들이 지각하는 생생함은 준사회적 상호작용 정도에도 영향을 미칠 것이다.

가설 3: 지각된 생생함은 지각된 사회적 실재감에 정 $(+)$ 의 영향을 미칠 것이다.

가설 4: 지각된 생생함은 지각된 집중된 주의에 정 $(+)$ 의 영향을 미칠 것이다.

가설 5: 지각된 생생함은 지각된 준사회적 상호작 용에 정 $(+)$ 의 영향을 미칠 것이다.

\section{4) Perceived interactivity}

지각된 상호작용성(perceived interactivity)은 SNS 브랜드 페이지를 통해서 소비자들이 브랜드 관계자 또는 다른 소비자들과 쌍방의 커뮤니케이션을 하는 느낌을 말한다. 많은 연구에서 상호작용성은 테크놀 로지 기기와의 상호작용 및 기기를 통한 커뮤니케이 션에서 중요한 요인이라는 것을 보여주었다(Coyle \& Thorson, 2001; Labrecque, 2014; McMillan \& Hwang, 2002; Park, 2008; Song \& Zinkhan, 2008; Yadav \& Varadarajan, 2005). 지각된 상호작용은 커뮤니케이션 에서 사용자의 조절능력, 쌍방의 피드백 및 피드백의 속도 등을 사용자가 지각하는 정도이다(McMillan \& Hwang, 2002; Song \& Zinkhan, 2008). 쌍방의 피드 백이 가능하지 않는 텔레비전, 라디오 등 기존의 전 통 매체와의 커뮤니케이션은 미디어로부터 일방적인 정보를 제공받는 사실상 일방적인 관계였으며(Auter, 1992), 웹사이트 및 웹광고 등의 디지털 환경에서의 커뮤니케이션 역시 사이트에 제시된 콘텐츠를 사용 자가 수용하고, 피드백의 속도가 느리다는 점에서 쌍 방의 상호작용과는 다소 거리가 있었다. 이에 비해 소셜 미디어 환경은 브랜드 관계자뿐만 아니라, 다수 의 소비자들이 자유롭게 소통하는 공간으로 모바일 기기를 통한 즉각적인 접속이 가능하고 새로운 콘텐 츠뿐만 아니라, 댓글이 제시되는 속도가 빠르며, 해시 태그 기능을 통해 다양한 플랫폼의 멀티미디어 정보 와의 자유로운 소통이 가능하다. 따라서 다른 매체에
비하여 소셜미디어 환경에서 소비자들의 지각된 쌍 방의 상호작용의 역할이 더욱 중요하다(Labrecque, 2014).

선행연구는 미디어 중재 커뮤니케이션 환경에서 사용자들의 지각된 상호작용은 유대감을 높이고, 가 상의 공간이 마치 실재 면대면 공간이라 느끼는 실존 감을 높이는 가장 중요한 요인이라는 것을 강조하였 다(Coyle \& Thorson, 2001; Fortin \& Dholakia, 2005; Shen \& Khalifa, 2012; Steuer, 1992). 지속적으로 제 공되는 컨텐츠와 신속한 쌍방의 피드백이 가능하며, 다양한 소비자들에 의해 쌓인 피드백을 볼 수 있는 $\mathrm{SNS}$ 브랜드 페이지에서 소비자들의 지각된 상호작용 성은 브랜드 페이지에 대한 주의를 집중시키고, 지각 된 사회적 실재감에 영향을 줄 것이다.

소셜미디어 환경에서 지각되는 상호작용은 해당 환경에서 커뮤니케이션 대상자와의 준사회적 상호작 용 느낌에 영향을 줄 수 있다. 선행연구는 사용자들 이 사용하는 매체와 상호작용, 즉 쌍방의 커뮤니케이 션이 이루어진다는 느낌이 강할수록 그 매체에 대하 여 높은 신뢰를 보이고 오랜 시간 이용하며, 호의적인 태도와 행동을 나타낸다는 것을 보여주었다(Voorveld, Neijens, \& Smit, 2009; Wang, Meng, \& Wang, 2013; $\mathrm{Wu}, \mathrm{Hu}, \& \mathrm{Wu}, 2010)$. Thorson and Rodgers(2006) 는 선거 후보자의 블로그에서 지각된 상호작용성이 높으면 블로그에서 보여주는 선거 후보자와 준사회 적 상호작용 관계를 강화시킨다는 것을 보여주며, 지 각된 상호작용의 직접적인 영향관계를 보여주었다 (Thorson \& Rodgers, 2006). Labrecque(2014)는 소셜 미디어 환경에서 소비자들이 사이트에 대한 지각된 상호작용이 높아질수록, 소비자들은 해당 브랜드와의 준사회적 상호작용 관계를 느낀다고 한다. SNS 브랜 드 페이지는 브랜드 관계자뿐만 아니라, 다른 소비자 들과의 상호작용이 이루어지는 커뮤니케이션 환경으 로 소비자들이 웹사이트와의 준사회적 상호작용을 느 낄 수 있는 것처럼(Hoerner, 1999), 브랜드 페이지에 서 준사회적 상호작용을 느낄 것이다. 이러한 준사회 적 상호작용은 브랜드 페이지에서 소비자들이 지각 된 상호작용에 의해 영향을 받을 것이다.

가설 6: 지각된 상호작용은 지각된 사회적 실재감 에 정(+)의 영향을 미칠 것이다. 
가설 7: 지각된 상호작용은 지각된 집중된 주의에 정 $(+)$ 의 영향을 미칠 것이다.

가설 8: 지각된 상호작용은 지각된 준사회적 상호 작용에 정 $(+)$ 의 영향을 미칠 것이다.

\section{Outcomes of perceived parasocial interaction}

소비자-브랜드 관계 형성의 성공적인 결과는 높 은 브랜드 충성도로 이어진다(Kim \& Chung, 2008; McAlexander, Schouten, \& Koening, 2002). 브랜딩 전략에서 가장 중요한 것 중 하나는 소비자와 브랜드 사이의 호의적이고 긴밀한 관계를 형성하는 것이다 (Fournier, 1998). 따라서 브랜드는 소비자들과 장기 간의 지속적이며 헌신적인 관계를 형성하고, 이를 통 해 브랜드 충성도를 높이고자 한다(Aaker, 1997). 긴 밀한 소비자-브랜드 관계의 형성은 감정적인 유대관 계를 통해 강화되며(Fournier, 1998), 이를 위해서는 지속적인 쌍방의 커뮤니케이션과 이를 통해 상호관 계에 대한 인식이 선행되어야 한다(Hunt \& Morgan, 1997). 본 연구에서는 호의적이며 지속적인 소비자-브 랜드 관계로 나타나는 소비자들의 브랜드 충성도 형 성에 소비자들이 브랜드 페이지에서 가상의 상호관 계에 대한 느낌인 준사회적 상호작용의 역할이 중요 할 것이라 제시한다. 소비자들이 지각하는 준사회적 상호작용의 결과로서 브랜드 페이지와의 감정적인 유 대관계인 인게이지먼트(affective engagement)와 브랜 드 충성도(brand loyalty)를 제시하고, 그 영향 관계를 알아보고자 한다.

\section{1) Affective engagement}

소비자들의 정서적 인게이지먼트(affective engagement)는 소비자가 브랜드, 매체 등 특정 대상과 상호 작용하는 경험에서 해당 브랜드 또는 매체와 정서적 인 애착을 느끼고, 지속적인 상호작용을 하고자 하는 정도를 말한다(Brodie, Hollebeek, Jurić, \& Ilić, 2011; Hollebeek, Glynn, \& Brodie, 2014). 본 연구에서 정 서적 인게이지먼트는 소비자들이 브랜드 페이지에서 제시된 콘텐츠, 다른 소비자들, 또는 브랜드 관련자들 과 상호작용을 하면서 브랜드 페이지에 대해서 느끼 는 정서적인 애착을 가지고, 지속적인 상호작용을 하 고자 하는 정도를 말한다. 정서적 인게이지먼트는 이 러한 지속적인 상호작용에서 심리적으로 동기부여
역할을 하며, 정서적인 유대와 감정적인 측면을 강조 한다(Brodie et al., 2011; Hollebeek et al., 2014). 인 게이지먼트는 소비자 참여(participation) 또는 관여 (involvement) 개념과는 달리 해당 대상과의 상호작 용을 통해서 얻는 개인의 상태이며, 지속적인 상호작 용을 통해 공동의 가치를 창조하는 소비자 경험을 반 영한다(Brodie et al., 2011; Calder, Malthouse, \& Schaedel, 2009). 소비자 만족(satisfaction), 브랜드 애 착(attachment), 브랜드 충성도(loyalty)와 같은 개념은 인게이지먼트의 결과적인 소비자 상태(Bowden, 2009a, 2009b; Calder et al., 2009)에 중점을 둔 반면, 인게이 지먼트는 브랜드 페이지와 같은 해당 대상과 상호작 용을 하는 소비자 경험 및 과정에 보다 중점을 둔다 (Calder et al., 2009; Mollen \& Wilson, 2010). 현재 소비자-브랜드 관계 형성에서 쌍방향의 상호작용, 특 히 소비자들의 주체적인 참여 및 역할이 중요해지면 서 인게이지먼트 개념이 더욱 중요해졌다(Hollebeek et al., 2014).

선행연구에 따르면 미디어 소비자들이 준사회적 상 호작용을 느끼면, 해당 미디어가 제공하는 가상의 사 회에서 일원처럼 느끼고, 이 과정에서 감정적인 즐거 움을 경험한다고 한다(Hartmann \& Goldhoorn, 2011). Men and Tsai(2013)는 소비자들이 기업의 SNS 팬페 이지에서 회사와의 준사회적 상호작용 관계를 강하 게 느낄수록 $\mathrm{SNS}$ 팬페이지에서 포스트 된 사진 및 정보를 읽어보는 단순한 소비행동에서 나아가 질문 을 하고 자신만의 콘텐츠를 만들어 업로드하며, 팬 페이지에서 보다 적극적으로 참여하고, 애착을 보이는 경향을 발견하였다. Horton and Wohl(1956)이 "intimacy at a distance"라고 설명한 것처럼, 미디어 소비자들이 준사회적 상호작용을 느낄수록 미디어 페르소나에 대 한 좋아하는 감정과 애착은 커진다(Perse \& Rubin, 1989). 따라서 소비자들이 브랜드 페이지와 상호작용 하며, 준사회적 상호작용을 느낄수록 브랜드 페이지 에 대한 정서적 인게이지먼트가 강화될 것이다.

가설 9: 지각된 준사회적 상호작용은 브랜드 페이 지와의 정서적 인게이지먼트에 정 $(+)$ 의 영향을 미칠 것이다.

\section{2) Brand loyalty}


브랜드 충성도는 소비자들이 브랜드 페이지를 제 공한 브랜드에 대한 충성도, 즉 해당 브랜드가 제공 하는 제품 또는 서비스를 지속적으로 이용하고, 타브 랜드의 마케팅전략에도 불구하고, 지속적인 헌신을 보여주는 것을 말한다(Oliver, 1999). 선행연구는 준 사회적 상호작용은 가상의 사회관계로서 준사회적 상 호작용을 강하게 느낄수록 소비자들은 그 관계를 유 지하고자 한다는 것을 보여준다(Tsiotsou, 2016). 즉, 소비자들이 준사회적 상호작용을 느낄수록 소비자들 은 미디어 소비를 늘리고, 적극적인 정보 습득 및 호 의적인 태도 및 행동의도가 높아진다는 것을 보여주 었으며(Rubin \& Step, 2000), 미디어 제공자에 대해 서 충성도가 커진다(Labrecque, 2014).

소셜미디어 환경은 소비자와 브랜드 관계자 또는 다른 소비자들과의 지속적인 소통이 가능한 공간을 제공하여 소셜미디어 사이트는 소비자들의 신뢰와 충 성도를 높이는 역할을 제공한다(Laroche, Habibi, \& Richard, 2013). 소비자-브랜드 관계의 질은 자발적이 고 지속적인 거래 또는 관계가 지속적이어야 높아진 다(Chang \& Chieng, 2006; Fournier, 1998). 특히 감 정적인 경험이 중요하며(Fournier, 1998), 소비자가 브 랜드와의 관계적 경험을 지각할 때 관계가 강화된다 (Schmitt, 1999). 예를 들어, 감정적인 애착 또는 헌신 은 소비자들의 심리적 친밀함을 높여 충성도를 높이 고(Bowden, 2009a, 2009b), 해당 브랜드를 지속적으 로 사용하고자 하는 의도를 높이는 결과에 영향을 준 다(Hollebeek et al., 2014). 전술된 내용을 바탕으로 다음과 같은 가설을 제시할 수 있다.

가설 10: 지각된 준사회적 상호작용은 브랜드 충성 도에 정 $(+)$ 의 영향을 미칠 것이다.

가설 11: 브랜드 페이지와의 정서적 인게이지먼트 는 브랜드 충성도에 정 $(+)$ 의 영향을 미칠 것이다.

\section{Methods}

\section{A proposed model of consumer-brand relationship} in SNS brand pages

본 연구는 SNS 브랜드 페이지가 소비자-브랜드 관 계 형성을 통한 충성도에 영향을 미치는 과정을 설명 하기 위하여 브랜드 페이지에서 소비자가 느끼는 준
사회적 상호작용의 역할을 제시하고자 하였다. 구체 적으로 브랜드 페이지 특성에 대한 소비자들의 느낌 (지각된 생생함, 지각된 상호작용성)과 브랜드 페이지 에서 소비자들이 경험한 지각된 실재감(사회적 실재 감, 집중된 주의)가 준사회적 상호작용에 영향을 미 치며, 지각된 준사회적 상호작용의 정도가 소비자들 의 감정적 인게이지먼트와 브랜드 충성도에 영향을 준다는 가설을 제시하였다. 제시된 가설을 토대로 〈Fig. 1〉에서 연구모형을 제시한다.

\section{Research procedure}

본 연구는 자기기입식 온라인 설문지법을 이용하 여 진행되었다. 온라인 설문 사이트 제작, 소비자 패 널 대상 설문 배포 및 수집은 국내 시장조사 전문회 사에서 담당하였다. 온라인 설문조사는 20 40대 남녀 소비자 중 패션 브랜드 팬 페이지를 적어도 1 개 이상 팔로우하는 소비자를 대상으로 하였다. 온라인 설문 사이트는 시장조사 전문회사가 보유한 소비자 패널에 배포되었으며, 연구조건에 부합하는 소비자들이 설문 에 참여하였다. 참여자들은 최근 방문한 패션 브랜드 팬 페이지에서의 경험에 대하여 환기하도록 요구되 었으며, 이를 바탕으로 설문에 응답하였다.

\section{Measures}

본 연구의 변수 측정에 사용된 설문 문항은 모두 선 행연구를 바탕으로 구성하였다. 본 연구의 주제인 온 라인 패션 브랜드 페이지에서의 소비자 경험에 맞게 수정되었으며, 모두 7점 Likert 척도로 측정되었다. 지 각된 생생함은 Petrova and Cialdini(2005)에서 사용된 항목을 사용하였으며, 지각된 상호작용성은 Jung, Hui, Min, and Martin(2014)에서 사용된 문항을 적용하였 다. 지각된 사회적 존재감은 Gefen and Straub(2003)의

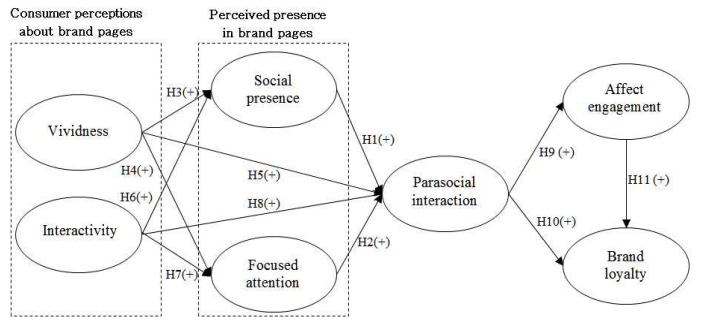

<Fig. 1> A proposed model 
문항을 사용하였으며, 집중된 주의는 Piyathasanan et al.(2015)의 문항을 이용하여 설문지를 구성하였다. 브 랜드 페이지와의 준사회적 상호작용(Labrecque, 2014), 브랜드 페이지에 대한 감정적 인게이지먼트(Hollebeek et al, 2014) 및 브랜드 충성도(Labrecque, 2014) 역시 선행연구에서 사용된 항목을 적용하여 구성하였다. 선 행연구에서 사용된 문항을 토대로 개발된 영문 설문지 는 역번역 과정을 통하여 한국어 설문지로 개발되었다 (Table 1).

\section{Sample characteristics}

본 연구의 온라인 설문조사에 참여한 전체 표본은 총 290 명이며, 조사대상자의 인구통계학적 특성은 다 음과 같다. 조사대상자의 평균 연령은 28 세였으며, 성
별 비율은 남성 $31 \%(90$ 명)와 여성 $69 \%(200$ 명)로서 여성 소비자가 많았으며, 미혼 $(82.8 \%, 240$ 명 $)$ 이 기혼 $(17.2 \%, 50$ 명 $)$ 보다 많았다. 최종학력은 대학교 졸업 이상이 $50.7 \%(147$ 명)로 가장 많았고, 대학교 재학 중 인 응답자가 $37.6 \%(109$ 명), 대학원 졸업 이상이 5.9\% (17명), 고등학교 졸업 이상이 5.9\%(17명)을 차지하였 다. 조사대상자들의 월평균 소득은 100 만원 이상 200 만원 미만이 $21.4 \%(62$ 명)로 가장 많았으며, 100 만원 미만이 20.7\%(60명), 200만원 이상 300 만원 이하에 속하는 소비자들이 $19.3 \%(56$ 명)로 많은 비율을 차지 하였으며, 다음으로 300 만원 이상 400 만원 미만 (12.8\%, 37명), 400만원 이상 500만원 미만(7.6\%, 22 명), 500 만원 이상 600 만원 미만(5.5\%, 16명), 600 만원 이상 700 만원 미만(5.5\%, 16명), 800 만원 이상 $(5.2 \%$,

$<$ Table 1> The results of confirmatory factor analysis

\begin{tabular}{|c|c|c|c|c|c|}
\hline Construct & Item & $\begin{array}{c}\text { Std. factor } \\
\text { loading }\end{array}$ & $t$ & $\alpha$ & $\mathrm{CR}$ \\
\hline \multirow{3}{*}{$\begin{array}{l}\text { Perceived } \\
\text { vividness }\end{array}$} & In general, the posts on this SNS were attention catching. & .85 & $16.73^{* * *}$ & \multirow{3}{*}{.76} & \multirow{3}{*}{.81} \\
\hline & In general, the posts on this SNS were exciting. & .93 & $19.14^{* * *}$ & & \\
\hline & In general, the posts on this SNS were detailed. & .47 & $8.10^{* * *}$ & & \\
\hline \multirow{2}{*}{$\begin{array}{l}\text { Perceived } \\
\text { interactivity }\end{array}$} & This SNS enabled two-way communication. & .91 & $19.28^{* * *}$ & \multirow{2}{*}{.89} & \multirow{2}{*}{.89} \\
\hline & This SNS was interactive. & .88 & $18.24^{* * *}$ & & \\
\hline \multirow{3}{*}{$\begin{array}{c}\text { Social } \\
\text { presence }\end{array}$} & There was a sense of human contact at this SNS site. & .89 & $18.99^{* * *}$ & \multirow{3}{*}{.91} & \multirow{3}{*}{.91} \\
\hline & There was a sense of personness at this SNS site. & .92 & $19.28^{* * *}$ & & \\
\hline & There was a sense of human warmth at this SNS site. & .84 & $17.22^{* * *}$ & & \\
\hline \multirow{3}{*}{$\begin{array}{l}\text { Focused } \\
\text { attention }\end{array}$} & I did not think about other things. & .78 & $15.29^{* * *}$ & \multirow{3}{*}{.85} & \multirow{3}{*}{.89} \\
\hline & I was focused on what I was doing. & .87 & $17.91^{* * *}$ & & \\
\hline & I was totally absorbed in what I was doing. & .89 & $18.64^{* * *}$ & & \\
\hline \multirow{5}{*}{$\begin{array}{l}\text { Parasocial } \\
\text { interaction }\end{array}$} & When I interact with this SNS, I feel included. & .73 & $14.08^{* * *}$ & \multirow{5}{*}{.92} & \multirow{5}{*}{.92} \\
\hline & I can relate to this $\mathrm{SNS}$. & .88 & $18.69^{* * *}$ & & \\
\hline & I like hearing what this SNS has to say. & .88 & $18.85^{* * *}$ & & \\
\hline & I care about what happens to this SNS. & .84 & $17.47^{* * *}$ & & \\
\hline & I hope this SNS can achieve its goals. & .83 & $17.19^{* * *}$ & & \\
\hline \multirow{3}{*}{$\begin{array}{c}\text { Affective } \\
\text { engagement }\end{array}$} & I feel very positive when I use this SNS. & .85 & $17.82^{* * *}$ & \multirow{3}{*}{.92} & \multirow{3}{*}{.92} \\
\hline & Using this SNS makes me happy. & .91 & $19.66^{* * *}$ & & \\
\hline & I feel good when I use this SNS. & .89 & $19.23^{* * *}$ & & \\
\hline \multirow{3}{*}{$\begin{array}{l}\text { Brand } \\
\text { loyalty }\end{array}$} & I'm willing to say positive things about this brand to others. & .88 & $18.16^{* * *}$ & \multirow{3}{*}{.88} & \multirow{3}{*}{.88} \\
\hline & I'm willing to encourage close others to do business with this brand. & .84 & $17.04^{* * *}$ & & \\
\hline & I plan to do business with this brand in the next few years. & .79 & $15.54^{* * *}$ & & \\
\hline
\end{tabular}
${ }^{* * *} p<.001$ 
15 명), 700 만원 이상 800 만원 미만 $(2.1 \%, 6$ 명)의 순이 었다. 응답자들의 직업은 학생 $(39 \%, 113$ 명 $)$, 사무/기 술직(37.6\%, 109명)으로 전체 응답자의 $76.6 \%$ 를 차지 하며 가장 많았다.

\section{Data Analyses and Results}

본 연구는 다수문항으로 측정된 구성개념들의 타 당성을 평가하기 위하여 확인적 요인분석(confirmatory factor analysis)을 실시하였으며, 본 연구에서 제시한 가설검증을 위하여 구조방정식모형 분석(structural equation modeling)을 실시하였다. 분석은 IBM Amos 21 프로그램을 활용하였다.

\section{Assessment of measurement model}

본 연구 구성개념에 대한 신뢰도와 타당도 검증을 위해서 확인적 요인분석을 실시하였다. 문제가 되는 항목을 제거한 수정된 측정모형의 적합도는 기준 이 상으로 나타나 적합하다고 판단하였다 $\left(\chi^{2}=462.009\right.$, $\mathrm{df}=246, \mathrm{p}<.001, \mathrm{CMIN} / \mathrm{DF}=1.878, \mathrm{SRMR}=.051, \mathrm{TLI}=$ $.955, \mathrm{CFI}=.963, \mathrm{RMSEA}=.055$ ). 〈Table 1〉에서 볼 수 있듯이, 각 항목의 구성개념에 대한 요인부하량(factor loading)은 모두 통계적으로 유의하였으며, 구성개념 의 신뢰도(Cronbach's $\alpha$, Construct Reliability: CR) 값은 .76이상이었으며, 평균분산추출(Average Variance Extracted: AVE)은 .60으로 나타나 수렴타당성(convergent validity)을 보여주었다. 또한 모든 개념의 $\mathrm{AVE}$ 값이 관련된 구성 개념간의 상관계수 제곱값보다 큰 것으로 나타나 판별타당성(discriminant validity)가 확 인되었다(Table 2).

\section{Hypotheses testing}

본 연구에서 제시된 가설을 검증하기 위하여 구조 방정식 모델 분석을 실시한 결과, 구조모형은 적합한 것으로 나타났다 $\left(\chi^{2}=614.749, \mathrm{df}=259, p<.001, \mathrm{CMIN} /\right.$ $\mathrm{DF}=2.374, \mathrm{SRMR}=.080, \mathrm{TLI}=.929, \mathrm{CFI}=.939$, RMSEA $=$ .069). 본 연구에서 모든 가설은 지지되었으며, 모형의 경로계수와 유의도는 〈Table 3 >과 같다. 가설 1 과 2 는 브랜드 페이지에서 소비자들이 느낀 사회적 실재감 과 집중된 주의가 준사회적 상호작용에 미치는 영향 에 대한 것으로, 지각된 사회적 실재감 $(\beta=.31, t=4.46$,
$<$ Table 2> Squared correlations between constructs and AVEs

\begin{tabular}{l|c|c|c|c|c|c|c}
\hline & $(1)$ & $(2)$ & $(3)$ & $(4)$ & $(5)$ & $(6)$ & $(7)$ \\
\hline Vividness (1) & $.60^{\mathrm{a}}$ & & & & & & \\
\hline Interactivity (2) & $.27^{\mathrm{b}}$ & .80 & & & & & \\
\hline Social presence (3) & .23 & .58 & .78 & & & & \\
\hline Focused attention (4) & .17 & .26 & .17 & .72 & & & \\
\hline Parasocial interaction (5) & .31 & .51 & .48 & .37 & .70 & & \\
\hline Affective engagement (6) & .46 & .53 & .47 & .35 & .66 & .78 & \\
\hline Brand loyalty (7) & .38 & .20 & .20 & .23 & .43 & .50 & .70 \\
\hline
\end{tabular}

a: Average Variance Extracted (AVE) for constructs are displayed on the diagonal.

b: Numbers below the diagonal are squared correlation estimates of two constructs.

$p<.001)$ 과 집중된 주의 $(\beta=.29, t=5.75, p<.001)$ 의 영 향은 모두 유의한 것으로 나타나 가설을 지지하였다. 즉, 소비자들이 브랜드 페이지에서 인간적이고 따뜻한 느낌을 느낄수록, 또한 브랜드 페이지에서의 활동에 집중한다고 느낄수록 브랜드 페이지와 마치 친구와 같 은 관계로 상호작용한다고 느낀다는 것을 보여준다.

가설 3 과 4는 브랜드 페이지에서 지각된 생생함이 브랜드 페이지와의 상호작용에서 소비자들이 지각하 는 사회적 실재감 $(\beta=.12, t=2.10, p<.05)$ 과 집중된 주 의 $(\beta=.21, t=3.00, p<.01)$ 에 미치는 영향에 관한 것으 로, 경로계수는 모두 정 $(+)$ 의 방향으로 유의하게 나타 나 가설을 지지하였다. 또한 가설 6과 7은 소비자들 이 지각하는 상호작용성이 브랜드 페이지에서 느끼는 사회적 실재감 $(\beta=.70, t=11.27, p<.001)$ 과 집중된 주 의 $(\beta=.40, t=5.70, p<.001)$ 에 미치는 영향에 관한 것 으로, 경로계수는 모두 정 $(+)$ 의 방향으로 유의하게 나 타나 가설을 지지하였다. 이 결과는 미디어에 중재된 가상의 공간에서 사용자들이 지각하는 생생함과 상호 작용성이 높을수록 마치 면대면 커뮤니케이션 관계와 유사하게 인간적인 느낌을 느끼고, 미디어 중재 커뮤 니케이션에 주의를 집중한다는 선행연구(Choi et al., 2001; Coyle \& Thorson, 2001; Steuer, 1992)를 지지 한다.

지각된 생생함 $(\beta=.20, t=3.98, p<.001)$ 과 지각된 상 호작용성 $(\beta=.25, t=3.32, p<.001)$ 이 지각된 브랜드 페 이지와의 준사회적 상호작용에 미치는 영향에 관한 
$<$ Table 3> Structural equation modeling results

\begin{tabular}{|c|c|c|c|c|}
\hline Structural paths & Coefficient & $\begin{array}{c}\text { Std. } \\
\text { coefficient }\end{array}$ & S.E. & $t$ \\
\hline H1: Social presence $\rightarrow$ Parasocial interaction & .29 & .31 & .07 & $4.46^{* * *}$ \\
\hline H2: Focused attention $\rightarrow$ Parasocial interaction & .27 & .29 & .05 & $5.75^{* * *}$ \\
\hline H3: Vividness $\rightarrow$ Social presence & .13 & .12 & .06 & $2.10^{*}$ \\
\hline H4: Vividness $\rightarrow$ Focused attention & .24 & .21 & .08 & $3.00^{* *}$ \\
\hline H5: Vividness $\rightarrow$ Parasocial interaction & .21 & .20 & .05 & $3.98^{* * *}$ \\
\hline H6: Interactivity $\rightarrow$ Social presence & 69 & .70 & .06 & $11.27^{* * *}$ \\
\hline H7: Interactivity $\rightarrow$ Focused attention & .41 & .40 & .07 & $5.70^{* * *}$ \\
\hline H8: Interactivity $\rightarrow$ Parasocial interaction & .23 & .25 & .07 & $3.32^{* * *}$ \\
\hline H9: Parasocial interaction $\rightarrow$ Affective engagement & .83 & .84 & .05 & $16.31^{* * *}$ \\
\hline H10: Parasocial interaction $\rightarrow$ Brand loyalty & .24 & .28 & .09 & $2.58^{* *}$ \\
\hline H11: Affective engagement $\rightarrow$ Brand loyalty & .41 & .46 & .09 & $4.38^{* * *}$ \\
\hline
\end{tabular}

경로계수는 모두 유의하게 나타나 가설 5 와 가설 8 을 지지하였다. 이 결과는 커뮤니케이션을 중재하는 미디 어가 보다 생생하고 상호작용을 하고 있다는 느낌이 강할수록 소비자들은 미디어와 커뮤니케이션 상대방 에 대하여 호의적인 감정을 느끼며, 마치 직접적 관계 속에 있는 것과 같은 준사회적 상호작용을 느낀다는 선 행연구 결과(Giles, 2002; Hoerner, 1999; Labrecque, 2014; Thorson \& Rodgers, 2006)를 지지하며, 패션 브랜드 페이지의 맥락에서 그 영향관계를 보여준다.

가설 9 와 10 은 소비자들이 SNS 브랜드 페이지에 서 지각하는 준사회적 상호작용이 감정적 인게이지 먼트 $(\beta=.84, t=16.31, p<.001)$ 와 브랜드 충성도 $(\beta=.28$, $t=2.58, p<.01)$ 에 미치는 영향에 관한 것이었고, 가설 11 은 브랜드 페이지에서 지각하는 감정적 인게이지 먼트가 브랜드 충성도 $(\beta=.46, t=4.38, p<.001)$ 에 미치 는 영향에 관한 것으로서, 경로계수는 모두 정 $(+)$ 의 방향으로 유의하게 나타나 가설을 지지하였다. 즉, $\mathrm{SNS}$ 브랜드 페이지와 심리적으로 형성된 가상의 사 회적 관계는 사이트에 대한 정서적 밀착관계뿐 아니 라, 사이트 제공자인 브랜드에 대한 충성도가 높아진 다는 것이다. 이 결과는 미디어 페르소나와의 준사회 적 상호작용이 정서적 밀착관계뿐 아니라, 미디어 소 비량에도 영향을 주며, 프로그램이 끝난 이후에도 지 속적인 의존 관계 형성에 영향을 준다는 준사회적 상 호작용 이론(Horton \& Wohl, 1956; Perse \& Rubin,
1989; Rubin et al., 1985; Skumanich \& Kintsfather, 1998)을 지지한다.

\section{Conclusion and Discussion}

본 연구는 성공적인 소비자-브랜드 관계 형성의 결 과인 브랜드 충성도에 영향을 줄 수 있는 SNS 브랜 드 페이지의 역할을 알아보았다. 특히 준사회적 상호 작용 이론을 이용하여 소비자들이 SNS 브랜드 페이 지에서 느낄 수 있는 준사회적 상호작용의 정도가 궁 극적으로 브랜드 충성도를 증진시킬 수 있음을 보여 주며, 브랜드 페이지 맥락에서 의사사회적 상호작용 이론(parasocial interaction theory)의 유용성을 검증 하였다. 즉, $\mathrm{TV}$, 라디오 등 전통 미디어의 등장인물 또는 미디어 제공자에 대해서 느끼는 가상적 관계를 뜻하는 준사회적 작용의 개념을 SNS 브랜드 페이지 라는 새로운 채널에서의 소비자 인지 경험으로 적용 시켜 확인한 것이다. 이 이론을 바탕으로 SNS 브랜드 페이지 환경에서의 소비자 경험이 어떻게 브랜드와 관계 형성에 영향을 미치는 지에 대하여 이론적 설명 을 부여하였다.

구체적으로 본 연구 결과를 요약하면 다음과 같다. 첫째, 브랜드 페이지와의 관계에서 느낄 수 있는 준 사회적 상호작용은 SNS 브랜드 페이지에 대한 소비 자들의 정서적 인게이지먼트를 높이고, 브랜드 충성 
도를 향상시키는 것을 보여주었다. 즉, 소비자들은 브 랜드 팬 페이지에 대하여 마치 친구와 같은 느낌을 느끼고, 이는 감정적인 애착으로 이어지며, 나아가 팬 페이지의 주체인 브랜드에 대한 충성도를 증진시키 는 것이다. 둘째, 본 연구는 소비자들이 SNS 브랜드 페이지에 대하여 느끼는 생생함과 상호작용성이 브 랜드 페이지에 머물면서 느끼는 사회적 실재감을 높 이고, 브랜드 페이지에서의 활동에 집중하고 몰입하 는 느낌을 증진시킨다는 것을 보여주었다. 연구 결과 는 이러한 느낌이 브랜드 페이지에 대한 준사회적 상 호작용 관계 정도에 영향을 주는 것을 보여주었다.

연구 결과를 바탕으로 다음과 같은 시사점을 찾을 수 있다. 첫째, 브랜드 충성도 제고에 SNS 브랜드 페 이지에서 활동하는 주요 소비자들의 행동과 인식에 대한 이해가 중요함을 강조한다. 구체적으로 본 연구 는 SNS 브랜드 팬 페이지의 효율성을 향상시키기 위 해서 브랜드 페이지를 친구와 같은 대상으로 만들 것 을 제안한다. 소비자들은 친구와 같은 브랜드 페이지 에서 애착관계를 형성하고, 해당 브랜드에 대하여 충 성도를 나타낸다. 이는 친구와 같은 브랜드 페이지 환경 조성을 위해서 브랜드의 타겟 소비자들에 대한 이해를 바탕으로 그들의 관심사, 라이프스타일, 미디 어 행태를 고려하여 브랜드 페이지를 디자인하고 운 영하는 활동이 효과적일 수 있음을 시사한다. 둘째, 본 연구 결과는 친구와 같은 팬 페이지 환경 디자인 을 위한 아이디어를 제공한다. 구체적으로 브랜드 페 이지 환경에서 포스팅 된 콘텐츠들이 보다 생생하게 느껴지고, 소비자들이 일방적 관계가 아닌 쌍방의 상 호관계를 느낄 수 있는 환경 제공이 중요함을 강조한 다. 이 결과를 토대로 마케터들은 소비자들이 지각하 는 생생함과 상호작용성을 높일 수 있도록 사이트에 서 생생한 콘텐츠를 제공하고, 빠른 피드백을 제시할 수 있는 방안을 강구하도록 노력해야 할 것이다. 예를 들어 인터랙티브 콘텐츠를 활용하고, 보다 구체적인 정보를 제공하여 소비자들이 느끼는 생생함을 증진 시킬 수 있을 것이다. 또한 소비자들로 하여금 보다 새롭고 인터랙티브한 콘테츠를 제공하도록 독려하고, 소비자들이 활용할 수 있는 관련 툴을 제공하는 방법 을 구상할 수 있을 것이다. 무엇보다 소셜미디어는 많은 소비자들의 활발한 참여가 중요한 공간이며, 소 비자들 간 상호작용성을 높일 수 있는 방법들을 지속
적으로 실험하고 제공하는 노력이 중요하다. 위치 기 반 서비스, 해시태그, 관련 이미지 검색 툴 등 소비자 들 및 게시글 간의 상호작용을 높일 수 있는 새로운 정보기술을 개발하고 활용하여 소비자들이 자신의 관심사를 중심으로 자발적인 참여를 촉진할 수 있는 판을 제공하도록 노력해야 할 것이다. 마지막으로, 인 간적인 따뜻함과 소비자들이 브랜드 페이지에서의 활동에 집중하고 주의하는 느낌을 제공하기 위하여, 검색 툴, 컨텐츠 종류 및 배치 등에 있어서 사용자 인 터페이스(UI)와 경험(UX)에 기반을 둔 페이지 디자 인이 중요함을 시사한다.

본 연구의 제한점 및 향후 연구방향을 제시하면 다 음과 같다. 첫째, 본 연구는 소비자들의 브랜드 페이 지에서 경험하면서 느끼는 준사회적 상호작용 및 느 낌에 대한 질문에서 과거의 경험을 회상하여 측정하 였다는 한계점을 지닌다. 과거의 경험에 대한 기억에 의존하는 것은 기억이 왜곡되었을 가능성이 존재하 며, 이에 따라 본 연구의 결과 해석시 주의가 필요하 다. 이 점을 보완하기 위해서 향후 사이트에서의 경 험에 대해서 측정하는 사이트에서의 경험을 한 직후 에 설문을 진행하거나, 사이트에서 경험을 하면서 동 시에 연구보조원이 면접법의 형식으로 질문하고 응 답을 받는 방법으로 연구를 진행할 수 있을 것이다. 둘째, 본 연구에서 설문 응답자들의 평균 나이는 28 세였다. 나이별 쿼터의 제한이 없었고, 패션 브랜드 페이지에 방문하는 소비자들은 비교적 젊다는 점에 서 자연스러운 결과일 수 있다. 하지만 디지털 기기 사용, SNS 관여도 및 브랜드에 대한 가치관/태도 등 은 세대별 상이할 수 있으므로, 본 연구 결과 해석에 는 주의가 필요하다. 향후 세대별 특성에 따라 패션 브랜드 페이지에서 소비자들이 지각하는 준사회적 상호작용이 어떤 역할을 하는 지 추가적인 연구가 필 요한 부분이다. 셋째, 본 연구에서는 응답자들에게 특 정 브랜드 페이지를 제시하지 않고, 응답자들이 최근 방문했던 브랜드 페이지에 대한 경험을 대상으로 설 문을 진행하였다. 이는 본 연구는 특정 브랜드의 특 성을 고려하기 보다는 SNS 브랜드 페이지에서 소비 자-브랜드 관계 형성의 과정을 설명하고자 하였기 때 문이다. 하지만, 브랜드에 따라 브랜드 개성, 이미지 등 아이덴티티가 상이하며, 이에 따라 팬 페이지의 특성, 즉 미디어 페르소나에 있어서 차이가 존재할 
수 있을 것이다. 따라서 향후 브랜드 특성을 고려하 여 본 연구 모형을 확대한 연구가 가능할 것이다.

\section{References}

Aaker, J. L. (1997). Dimensions of brand personality. Journal of Marketing Research, 34(3), 347-356. doi: $10.2307 / 3151897$

Auter, P. J. (1992). Psychometric: TV that talks back: An experimental validation of a parasocial interaction scale. Journal of Broadcasting \& Electronic Media, 36(2), 173-181. doi:10.1080/08838159209 364165

Ballantine, P. W., \& Martin, B. A. S. (2005). Forming parasocial relationships in online communities. Advances in Consumer Research, 32(1), 197-201.

Biocca, F., \& Delaney, B. (1995). Immersive virtual reality technology. In F. Biocca \& M. R. Levy (Eds.), Communication in the age of virtual reality (pp. 57-124). Hillsdale, NJ: Lawrence Erlbaum Associates.

Bowden, J. (2009a). Customer engagement: A framework for assessing customer-brand relationships: The case of the restaurant industry. Journal of Hospitality Marketing \& Management, 18(6), 574596. doi:10.1080/19368620903024983

Bowden, J. L.-H. (2009b). The process of customer engagement: A conceptual framework. Journal of Marketing Theory and Practice, 17(1), 63-74.

Bracken, C. C., Pettey, G., \& Wu, M. (2014). Revisiting the use of secondary task reaction time measures in telepresence research: Exploring the role of immersion and attention. AI \& Society, 29(4), 533-538. doi:10.1007/s00146-013- 0494-7

Brodie, R. J., Hollebeek, L. D., Jurić, B., \& Ilić, A. (2011). Customer engagement: Conceptual domain, fundamental propositions, and implications for research. Journal of Service Research, 14(3), 252271. doi:10.1177/1094670511411703

Calder, B. J., Malthouse, E. C., \& Schaedel, U. (2009). An experimental study of the relationship between online engagement and advertising effectiveness. Journal of Interactive Marketing, 23(4), 321-331. doi:10.1016/j.intmar.2009.07.002

Carù, A., \& Cova, B. (2006). How to facilitate immersion in a consumption experience: Appropriation operations and service elements. Journal of Consumer Behaviour, 5(1), 4-14. doi:10.1002/cb.30

Chang, P.-L., \& Chieng, M.-H. (2006). Building consumer-brand relationship: A cross-cultural experiential view. Psychology \& Marketing, 23(11), 927-959. doi:10.1002/mar.20140

Choi, Y. K., Miracle, G. E., \& Biocca, F. (2001). The effects of anthropomorphic agents on advertising effectiveness and the mediating role of presence. Journal of Interactive Advertising, 2(1), 19-32. doi:10.1080/15252019.2001.10722055

Coyle, J. R., \& Thorson, E. (2001). The effects of progressive levels of interactivity and vividness in web marketing sites. Journal of Advertising, 30(3), 65-77. doi:10.1080/00913367.2001.10673646

Daft, R. L., \& Lengel, R. H. (1986). Organizational information requirements, media richness and structural design. Management Science, 32(5), 554-571. doi:10.1287/mnsc.32.5.554

Daft, R. L., Lengel, R. H., \& Trevino, L. K. (1987). Message equivocality, media selection, and manager performance: Implications for information systems. MIS Quarterly, 11(3), 355-366. doi:10.2307/248682

Fortin, D. R., \& Dholakia, R. R. (2005). Interactivity and vividness effects on social presence and involvement with a web-based advertisement. Journal of Business Research, 58(3), 387-396. doi:10.1016/ S0148-2963(03)00106-1

Fournier, S. (1998). Consumers and their brands: Developing relationship theory in consumer research. Journal of Consumer Research, 24(4), 343-373. doi:10.1086/209515

Gefen, D., \& Straub, D. (2003). Managing user trust in B2C e-services. e-Service Journal, 2(2), 7-24. doi:10.2979/esj.2003.2.2.7

Giles, D. C. (2002). Parasocial interaction: A review 
of the literature and a model for future research. Media Psychology, 4(3), 279-305. doi:10.1207/ S1532785XMEP0403_04

Goldstein, E. B. (2007). Sensation and perception (7th ed.). Belmont, CA: Thomson Wadsworth.

Hartmann, T., \& Goldhoorn, C. (2011). Horton and Wohl revisited: Exploring viewers' experience of parasocial interaction. Journal of Communication, 61(6), 1104-1121. doi:10.1111/j.1460-2466.2011. 01595.x

Hennig-Thurau, T., Malthouse, E. C., Friege, C., Gensler, S., Lobschat, L., Rangaswamy, A., \& Skiera, B. (2010). The impact of new media on customer relationships. Journal of Service Research, 13(3), 311-330. doi:10.1177/1094670510375460

Hoerner, J. (1999). Scaling the web: A parasocial interaction scale for world wide web sites. In D. W. Schumann \& E. Thorson (Eds.), Advertising and the world wide web (pp. 135-147). Mahwah, NJ: Lawrence Erlbaum Associates.

Hollebeek, L. D., Glynn, M. S., \& Brodie, R. J. (2014). Consumer brand engagement in social media: Conceptualization, scale development and validation. Journal of Interactive Marketing, 28(2), 149-165. doi:10.1016/j.intmar.2013.12.002

Horton, D., \& Wohl, R. R. (1956). Mass communication and para-social interaction: Observations on intimacy at a distance. Psychiatry, 19(3), 215-229. doi:10.1080/00332747.1956.11023049

Huang, L.-T. (2016). Flow and social capital theory in online impulse buying. Journal of Business Research, 69(6), 2277-2283. doi:10.1016/j.jbusres. 2015.12.042

Hunt, S. D., \& Morgan, R. M. (1997). Resourceadvantage theory: A snake swallowing its tail or a general theory of competition?. Journal of Marketing, 61(4), 74-82. doi:10.2307/1252088

Jin, S.-A. A. (2010). Parasocial interaction with an avatar in second life: A typology of the self and an empirical test of the mediating role of social presence. Presence: Teleoperators and Virtual
Environments, 19(4), 331-340. doi:10.1162/PRES a_00001

Johnson, A. \& Proctor, R. W. (2004). Attention: Theory and practice. Thousand Oaks, CA: Sage Publications.

Jung, J. M., Hui, H. C., Min, K. S., \& Martin, D. (2014). Does telic/paratelic user mode matter on the effectiveness of interactive internet advertising? A reversal theory perspective. Journal of Business Research, 67(6), 1303-1309. doi:10.1016/j.jbusres. 2013.03.002

Kalehoff, M. (2013, July 2). People 'fan' brands because they actually like them. MediaPost, Retrieved April 26, 2016, from http://www.mediapost.com/publi cations/article/203748/people-fan-brands-becausethey-actually-like-the.html\#axzz2Xu09Zi45

Kim, S.-J., \& Chung, M.-S. (2008). The effect of consumer-brand relationship of fashion luxury product on brand loyalty. The Research Journal of the Costume Culture, 16(6), 1076-1086.

Koenig, F., \& Lessan, G. (1985). Viewers' relationship to television personalities. Psychological Reports, 57(1), 263-266. doi:10.2466/pr0.1985.57.1.263

Labrecque, L. I. (2014). Fostering consumer-brand relationships in social media environments: The role of parasocial interaction. Journal of Interactive Marketing, 28(2), 134-148. doi:10.1016/j.intmar. 2013.12.003

Lang, A. (1990). Involuntary attention and physiological arousal evoked by structural features and emotional content in TV commercials. Communication Research, 17(3), 275-299. doi:10.1177/009365090017003001

Laroche, M., Habibi, M. R., \& Richard, M.-O. (2013). To be or not to be in social media: How brand loyalty is affected by social media?. International Journal of Information Management, 33(1), 76-82. doi:10.1016/j.ijinfomgt.2012.07.003

Lee, K. M., Peng, W., Jin, S.-A., \& Yan, C. (2006). Can robots manifest personality?: An empirical test of personality recognition, social responses, and social presence in human-robot interaction. Journal 
of Communication, 56(4), 754-772. doi:10.1111/ j.1460-2466.2006.00318.x

Lee, Y., \& Cho, N. H. (2014). The relationship of the characteristics of fashion brand SNS, relationship quality and purchase intention: Focusing on Facebook. The Research Journal of the Costume Culture, 22(5), 834-847. doi:10.7741/rjcc.2014.22.5.834

Levy, M. R. (1979). Watching TV news as para-social interaction. Journal of Broadcasting \& Electronic Media, 23(1), 69-80. doi:10.1080/088381579093 63919

Lombard, M., \& Ditton, T. (1997). At the heart of it all: The concept of presence. Journal of ComputerMediated Communication, 3(2), 0-0. doi:10.1111/ j.1083-6101.1997.tb00072.x

McAlexander, J. H., Schouten, J. W., \& Koening, H. F. (2002). Building brand community. Journal of Marketing, 66(1), 38-54. doi:10.1509/jmkg.66.1.38. 18451

McMillan, S. J., \& Hwang, J.-S. (2002). Measures of perceived interactivity: An exploration of the role of direction of communication, user control, and time in shaping perceptions of interactivity. Journal of Advertising, 31(3), 29-42. doi:10.1080/009133 67.2002. 10673674

Men, L. R., \& Tsai, W.-H. S. (2013). Beyond liking or following: Understanding public engagement on social networking sites in China. Public Relations Review, 39(1), 13-22. doi:10.1016/j.pubrev.2012. 09.013

Mollen, A., \& Wilson, H. (2010). Engagement, telepresence and interactivity in online consumer experience: Reconciling scholastic and managerial perspectives. Journal of Business Research, 63 (9/10), 919-925. doi:10.1016/j.jbusres.2009.05.014

Nass, C., \& Moon, Y. (2000). Machines and mindlessness: Social responses to computers. Journal of Social Issues, 56(1), 81-103. doi:10.1111/00224537.00153

Novak, T. P., Hoffman, D. L., \& Yung, Y.-F. (2000). Measuring the customer experience in online en- vironments: A structural modeling approach. Marketing Science, 19(1), 22-42. doi:10.1287/mksc. 19.1.22.15184

Oliver, R. L. (1999). Whence consumer loyalty?. Journal of Marketing, 63, 33-44. doi:10.2307/1252099

Park, M. (2008). The role of interactivity in online shopping environments. The Research Journal of the Costume Culture, 16(1), 145-157.

Perse, E. M., \& Rubin, R. B. (1989). Attribution in social and parasocial relationships. Communication Research, 16(1), 59-77. doi:10.1177/0093650890 16001003

Petrova, P. K., \& Cialdini, R. B. (2005). Fluency of consumption imagery and the backfire effects of imagery appeals. Journal of Consumer Research, 32(3), 442-452. doi:10.1086/497556

Piyathasanan, B., Mathies, C., Wetzels, M., Patterson, P. G., \& de Ruyter, K. (2015). A hierarchical model of virtual experience and its influences on the perceived value and loyalty of customers. International Journal of Electronic Commerce, 19(2), 126-158.

Powell, L., Richmond, V. P., \& Williams, G. C. (2011). Social networking and political campaigns: Perceptions of candidates as interpersonal constructs. North American Journal of Psychology, 13(2), 331-342.

Reeves, B., \& Nass, C. (1996). The media equation: How people treat computers, television, and new media like real people and places. Cambridge, UK: CSLI Publications and Cambridge University Press.

Rice, R. E. (1992). Task analyzability, use of new media, and effectiveness: A multi-site exploration of media richness. Organization Science, 3(4), 475500. doi:10.1287/orsc.3.4.475

Rubin, A. M., \& Perse, E. M. (1987a). Audience activity and soap opera involvement: A uses and effects investigation. Human Communication Research, 14(2), 246-268. doi:10.1111/j.1468-2958.1987.tb00129.x

Rubin, A. M., \& Perse, E. M. (1987b). Audience activity and television news gratifications. Com- 
munication Research, 14(1), 58-84. doi:10.1177/ 009365087014001004

Rubin, A. M., \& Step, M. M. (2000). Impact of motivation, attraction, and parasocial interaction on talk radio listening. Journal of Broadcasting \& Electronic Media, 44(4), 635-654. doi:10.1207/ s15506878jobem4404_7

Rubin, A. M., Perse, E. M., \& Powell, R. A. (1985). Loneliness, parasocial interaction, and local television news viewing. Human Communication Research, 12(2), 155-180. doi:10.1111/j.1468-2958. 1985.tb00071.x

Schmitt, B. H. (1999). Experiential marketing: How to get customer to sense, feel, think, act, and relate to your company and brands. New York: The Free Press.

Shen, K. N., \& Khalifa, M. (2012). System design effects on online impulse buying. Internet Research, 22(4), 396-425. doi:10.1108/10662241211250962

Short, J., Williams, E., \& Christie, B. (1976). The social psychology of telecommunication. London: Wiley.

Skumanich, S. A., \& Kintsfather, D. P. (1998). Individual media dependency relations within television shopping programming: A causal model reviewed and revised. Communication Research, 25(2), 200219. doi:10.1177/009365098025002004

Song, J. H., \& Zinkhan, G. M. (2008). Determinants of perceived web site interactivity. Journal of Marketing, 72(2), 99-113. doi:10.1509/jmkg.72.2.99

Statista. (2016a). Number of social network users worldwide from 2010 to 2019 (in billions). Statista, Retrieved April 26, 2016, from http://www.statista. com/statistics/278414/number-of-worldwide-socia 1-network-users

Statista. (2016b). Statistics and facts about brands on social media. Statista, Retrieved March 28, 2016, from http://www.statista.com/topics/2057/brands-onsocial-media

Stephens, D. L., Hill, R. P., \& Bergman, K. (1996).
Enhancing the consumer-product relationship: Lessons from the QVC home shopping channel. Journal of Business Research, 37(3), 193-200. doi:10.1016/S0148-2963(96)00069-0

Stern, B. B., Russell, C. A., \& Russell, D. W. (2007). Hidden persuasions in soap operas: Damaged heroines and negative consumer effects. International Journal of Advertising, 26(1), 9-36.

Steuer, J. (1992). Defining virtual reality: Dimensions determining telepresence. Journal of Communication, 42(4), 73-93. doi:10.1111/j.1460-2466.1992.tb00812.x

Thorson, K. S., \& Rodgers, S. (2006). Relationships between blogs as eWOM and interactivity, perceived interactivity, and parasocial interaction. Journal of Interactive Advertising, 6(2), 5-44. doi:10.1080/ 15252019.2006.10722117

Tsiotsou, R. H. (2016). The social aspects of consumption as predictors of consumer loyalty: Online vs offline services. Journal of Service Management, 27(2), 91-116. doi:10.1108/JOSM-04-2015-0117

Voorveld, H. A. M., Neijens, P. C., \& Smit, E. G. (2009) Consumers' responses to brand websites: An interdisciplinary review. Internet Research, 19 (5), 535-565. doi:10.1108/10662240920998887

Wang, H., Meng, Y., \& Wang, W. (2013). The role of perceived interactivity in virtual communities: Building trust and increasing stickiness. Connection Science, 25(1), 55-73. doi:10.1080/09540091.2013. 824407

Wu, G., Hu, X., \& Wu, Y. (2010). Effects of perceived interactivity, perceived web assurance and disposition to trust on initial online trust. Journal of Computer-Mediated Communication, 16(1), 1-26. doi:10.1111/j.1083-6101.2010.01528.x

Yadav, M. S., \& Varadarajan, R. (2005). Interactivity in the electronic marketplace: An exposition of the concept and implications for research. Journal of the Academy of Marketing Science, 33(4), 585603. doi:10.1177/0092070305278487 